\title{
Effects of Makeup Application on Diverting the Gaze of Others from Areas of Inflammatory Lesions in Patients with Acne Vulgaris
}

\author{
Yumi Murakami-Yoneda1, Mieko Hata ${ }^{2}$, Yoshie Shirahige', Kozo Nakai', Yasuo Kubota1* \\ ${ }^{1}$ Department of Dermatology, Faculty of Medicine, Kagawa University, Kagawa, Japan \\ ${ }^{2}$ Department of Dermatology, Nippon Medical School, Tokyo, Japan \\ Email: ${ }^{*}$ kubotay@med.kagawa-u.ac.jp
}

Received 26 May 2015; accepted 22 June 2015; published 26 June 2015

Copyright (C) 2015 by authors and Scientific Research Publishing Inc.

This work is licensed under the Creative Commons Attribution-NonCommercial International License (CC BY-NC).

http://creativecommons.org/licenses/by-nc/4.0/

(c) $)$ (i) (9) Open Access

\section{Abstract}

Skin manifestations can be major sources of stress for patients with skin diseases; hence, the effective use of makeup and cosmetic products for these patients has been established. The objective of this study was to determine if makeup can divert observers' gaze from areas of inflammatory acne lesions. Both base and point makeup were applied to two Japanese female patients with mild to moderate acne vulgaris to hide skin manifestations, as well as to accentuate the eyes and lips. Photographs of their faces were shown, at various stages of makeup application, to $22 \mathrm{ob}-$ servers (11 men and 11 women). The effects of makeup application, and other eye-diverting strategies (e.g., clothing, accessories, and hairstyle), used to draw observers' gaze away from acne lesions, were evaluated by analyzing observers' eye movements. As base makeup application proceeded, time to first fixation, total fixation duration, and fixation count changed. Compared to "no makeup", the time to first fixation, total fixation duration, and fixation count also decreased significantly after point makeup application. The additional eye-diverting strategies used also had significant gaze-diverting effects. Therefore, makeup can be useful for patients with acne to divert others' gaze from lesions. Therefore, it should be actively integrated into acne management.

\section{Keywords}

Acne Vulgaris, Eye Tracking, Base Makeup, Point Makeup, Gaze Diversion

\footnotetext{
${ }^{*}$ Corresponding author.

How to cite this paper: Murakami-Yoneda, Y., Hata, M., Shirahige, Y., Nakai, K. and Kubota, Y. (2015) Effects of Makeup Application on Diverting the Gaze of Others from Areas of Inflammatory Lesions in Patients with Acne Vulgaris. Journal of Cosmetics, Dermatological Sciences and Applications, 5, 134-141. http://dx.doi.org/10.4236/jcdsa.2015.52016
} 


\section{Introduction}

In dermatological therapy, cosmetic makeup is considered to exacerbate skin problems on the face. Therefore, patients are generally advised not to use it. However, patients with skin diseases and lesions that are difficult to treat or are incurable, such as vitiligo and scars, can achieve improved quality of life (QOL) when instructed to apply makeup to make skin manifestations less noticeable. The usefulness and safety of makeup and cosmetic products for patients with some skin diseases have been reported [1] [2]. For example, patients with atopic dermatitis and acne vulgaris, who apply makeup under the instruction of dermatologists, report improved QOL [3]-[5]. For patients with skin diseases, the skin manifestations themselves and other people looking at them can be major sources of psychological stress, negatively affecting patient QOL. Moreover, for adult women, the dermatologist-directed prohibition of makeup, which is a part of their personal daily grooming routine, can also become another source of stress.

Makeup can be broadly classified as base makeup and point makeup. Base makeup application can hide skin manifestations, while using point makeup, to accentuate the eyes and lips, can divert the gaze of other people from skin lesions and the affected areas. Thus, patients who are aware of this potential benefit of makeup can improve their QOL [5]. Although previous studies have verified the positive effects of makeup application on the QOL of patients with skin diseases, whether makeup can divert the gaze of other people from skin lesions has not been examined in detail.

Eye-tracking systems have recently enabled the recording and analysis of eye gaze movements and are already being applied in consumer psychology and public marketing research [6] [7]. Eye-tracking systems have also been used to evaluate skin features, such as pigmented lesions and acne vulgaris [8] [9].

Therefore, the present study investigated the ability of makeup application and other diversion strategies, such as hairstyle, to divert the gaze of others from areas affected by skin diseases.

\section{Methods}

\subsection{Patients and Photography}

Makeup was applied to a 25-year-old Japanese woman with moderate acne (woman A) and a 23-year-old Japanese woman with mild acne (woman B) in May 2012. Acne severity was determined on the basis of the Japanese Dermatological Association's criteria for acne severity [10]. The women were photographed at different stages of base and point makeup application. They were also photographed wearing different clothes, accessories, or a different hairstyle, or with all of these elements combined. For photography, the women were positioned away from windows to avoid exposure to direct natural light; indoor lighting, from below and above, was used so their faces were unshaded when photographed. They sat facing forward and looked directly into the camera (Canon Inc., Tokyo, Japan) viewfinder to adjust the observer’s line of sight. Afterward, Casmatch ${ }^{\circledR}$ (Medical Bear Co., Ltd., Gunma, Japan) in Adobe Photoshop ${ }^{\circledR}$ (Adobe Systems Incorporated, San Jose, CA, USA) was used to edit image color for uniformity of tone and to ensure equal sizing. Written informed consent was obtained from both women, after receiving oral and written explanations of the study. The study was approved by the ethics committee.

\subsection{Base and Point Makeup}

All makeup products were made by Tokiwa Pharmaceutical Co., Ltd. (Tokyo, Japan). The base makeup consisted of a base control color that corrects for redness and skin rash ( $\mathrm{NOV}^{\circledR}$ base control color, natural yellow), a concealer that covers areas of particularly strong redness (NOV concealer), and a powder foundation (NOV powdery foundation UV) used to prepare the texture of the skin. Successive images were taken at each stage (A-1 to A-4, respectively). The point makeup consisted of an eyebrow pencil (NOV eyebrow), an eye color product (NOV eye color), and a lipstick (NOV lipstick).

\subsection{Observation Subjects}

The observation study was performed in July 2012. There were a total of 22 observers (11 men and 11 women). The intent of the evaluation was not explained to the observers. The observers were instructed to look at the im- 
ages of the women as if they were meeting them for the first time.

\subsection{Gaze Movement Measurement}

Points of gaze fixation were detected by using an eye tracker attached to an LCD (Tobii T120; Tobii Technology AB, Danderyd, Sweden) in order to measure the movements of the observers' eyes while they evaluated the women's faces. During the measurements, a blue cloth covered the left and right sides of the display so that only the women's face was in the field of view. The display was placed $600 \mathrm{~mm}$ in front of the observers' eyes. The images were displayed for $8 \mathrm{~s}$ each, at 2s-intervals. Four images were examined per session.

A region of interest analysis was performed. Briefly, several parts of the image of the women's faces were sectionalized, and the area with the most acne (i.e., the right cheek) was established for the analysis. Tobii Studio analysis software (Tobii Technology $\mathrm{AB}$ ) was used for the analysis. To verify gaze movements away from areas of acne eruption, the right cheek, which had no moles or other marks, was defined as the acne area. In this eye tracker system, green circles on the photographs of the women's faces indicate an observer looked at the area, while red circles indicate observers gazed at the area with greater attention. These "green" and "red" areas were defined as a "visit" and a "fixation", respectively. An image of the heat map is shown in Figure 1.

The following markers were analyzed: a) the number of observers who fixed their gaze on the acne area; b) the time to first fixation (i.e., the time elapsed before the observer fixed their gaze on the acne area for the first time); c) total fixation duration (i.e., the total amount of time the observer's gaze remained fixed on the acne area); and d) fixation count (i.e., the number of times the observer fixed their gaze on the acne area).

\subsection{Statistical Analysis}

Data were analyzed using the Wilcoxon signed-rank test. The Steel-Dwass test was used for multiple comparisons. The level of significance was set at $P<0.05$.

\section{Result}

\subsection{Effects of Base Makeup Application (Figure 2, Table 1)}

\section{- Number of observers}

As the base makeup process proceeded from A-1 to A-4, the number of observers who fixed their gaze at the acne-affected area decreased slightly: 22, 20,18, and 19 observers fixated their gaze on the acne-affected area in A-1 through A-4, respectively.

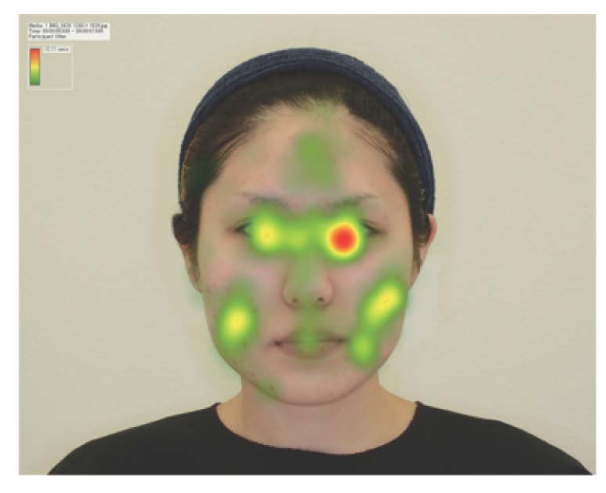

Indicating the concentration of the gaze.



Figure 1. Heat map image. 


\section{- Time to first fixation}

Greater time to first fixation indicates the observers' gaze was fixated less on the acne-affected area on the right cheek. The times to first fixation from A-1 to A-4 tended to increase, but the differences were not significant $(P>0.05)$.

\section{- Total fixation duration}

Shorter total fixation duration indicates less time was spent with the gaze fixed at the inflammatory acne eruptions. The total fixation from A-1 to A-4 tended to decrease. The total fixation duration in A-4 was significantly shorter than that in A-1 (no makeup) $(P=0.045)$.

\section{- Fixation count}

A lower fixation count indicates the observers' gaze was fixed at the acne-affected area on the right cheek fewer times. The fixation count tended to decrease from A-1 to A-4, but the differences were not significant $(P>$ $0.05)$.

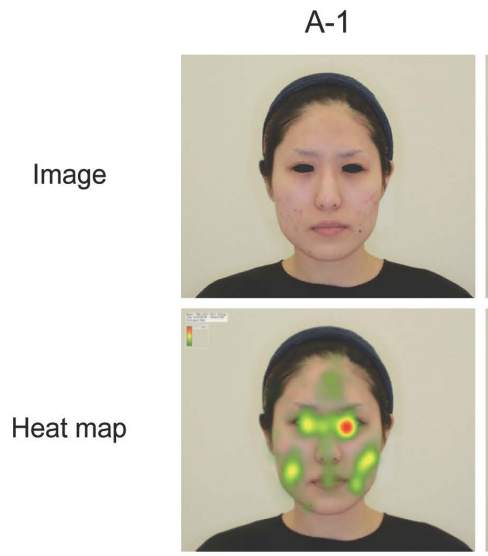

No makeup



A-1

Makeup base (control color)
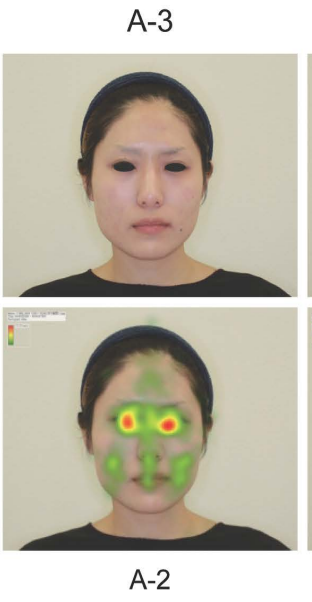

Concealer

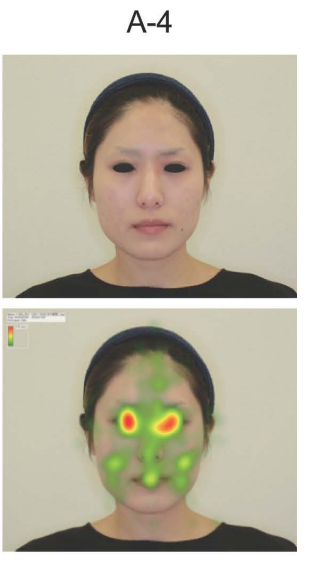

A-3

Foundation

Figure 2. Base makeup images.

Table 1. Effects of base makeup.

\begin{tabular}{|c|c|c|c|c|c|c|c|c|}
\hline & & \multirow{2}{*}{$\begin{array}{c}\text { Fixation } \\
\text { number } \\
(n)\end{array}$} & \multicolumn{2}{|c|}{$\begin{array}{l}\text { Time to first fixation } \\
\text { (s) }\end{array}$} & \multicolumn{2}{|c|}{$\begin{array}{l}\text { Total fixation duration } \\
\text { (s) }\end{array}$} & \multicolumn{2}{|c|}{$\begin{array}{l}\text { Fixation count } \\
(n)\end{array}$} \\
\hline & & & Mean & SE & Mean & SE & Mean & SE \\
\hline A-1 & No makeup & $22 / 22$ & 2.26 & 0.22 & 0.74 & 0.09 & 2.59 & 0.29 \\
\hline A-2 & $\begin{array}{l}\text { A-1 + makeup base } \\
\text { (control color) }\end{array}$ & $20 / 22$ & 2.96 & 0.36 & 0.69 & 0.13 & 2.18 & 0.31 \\
\hline A-3 & A-2 + concealer & $18 / 22$ & 2.74 & 0.35 & 0.47 & 0.13 & 1.68 & 0.35 \\
\hline A-4 & A-3 + foundation & $19 / 22$ & 3.40 & 0.41 & 0.46 & 0.11 & 1.59 & 0.28 \\
\hline \multirow{6}{*}{$P$ value } & A-1 vs. A-2 & & 0.627 & N.S. & 0.839 & N.S. & 0.775 & N.S. \\
\hline & A-1 vs. A-3 & & 0.571 & N.S. & 0.057 & N.S. & 0.125 & N.S. \\
\hline & A- 1 vs. A-4 & & 0.087 & N.S. & 0.045 & * & 0.053 & N.S. \\
\hline & A-2 vs. A-3 & & 0.998 & N.S. & 0.351 & N.S. & 0.573 & N.S. \\
\hline & A-2 vs. A-4 & & 0.691 & N.S. & 0.353 & N.S. & 0.457 & N.S. \\
\hline & A- 3 vs. A- 4 & & 0.745 & N.S. & 0.997 & N.S. & 1.000 & N.S. \\
\hline
\end{tabular}

\footnotetext{
${ }^{* *} P<0.01,{ }^{*} P<0.05$.
} 


\subsection{Effects of Point Makeup Application (Figure 3, Table 2)}

\section{- Number of observers}

There were 22, 19, 9, and 15 observers who fixated on the acne-affected area in A-1, A-4, A-5, and A-6, respectively; 15 and 8 observers fixated on the acne-affected area in B-1 and B-2, respectively. Thus, the application of point makeup resulted in fewer observers fixing their gaze on the acne-affected area in both woman $\mathrm{A}$ and B.

\section{- Time to first fixation}

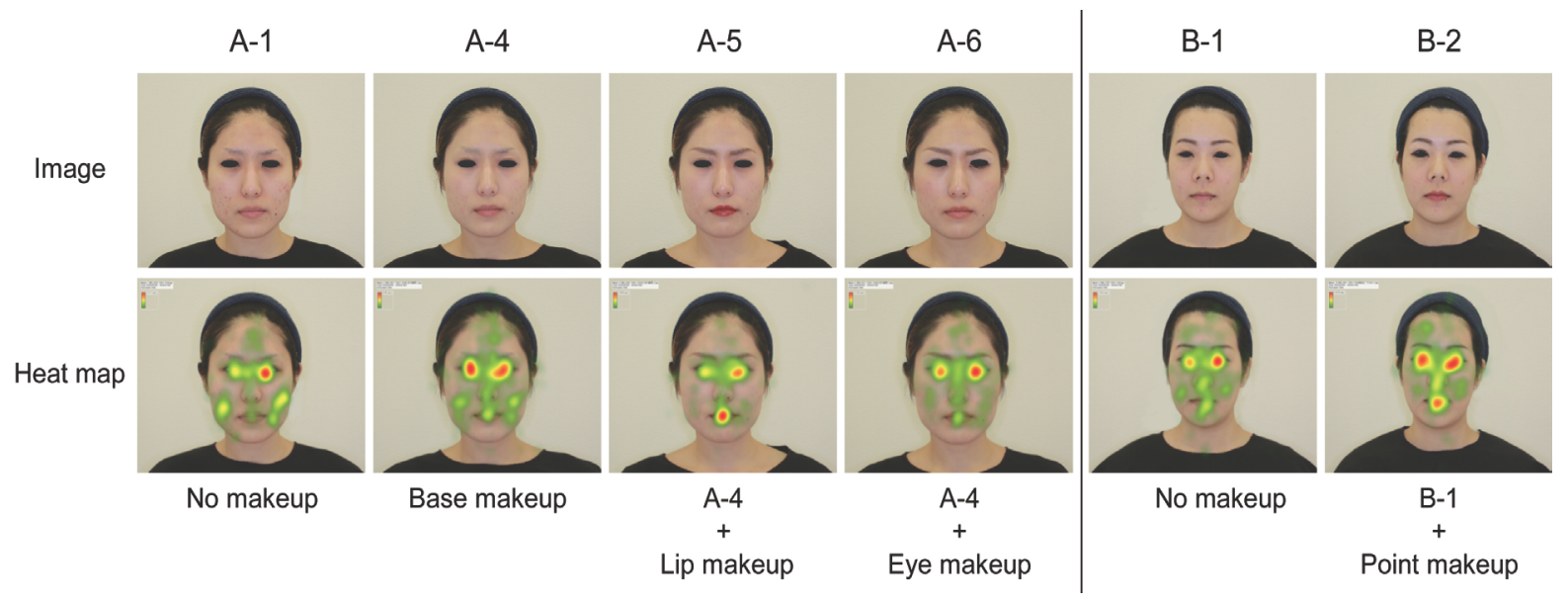

Figure 3. Point makeup images.

Table 2. Effects of point makeup.

\begin{tabular}{|c|c|c|c|c|c|c|c|c|}
\hline & & \multirow{2}{*}{$\begin{array}{c}\text { Fixation } \\
\text { number } \\
\text { (n) }\end{array}$} & \multicolumn{2}{|c|}{$\begin{array}{l}\text { Time to first fixation } \\
\text { (s) }\end{array}$} & \multicolumn{2}{|c|}{$\begin{array}{l}\text { Total fixation duration } \\
\text { (s) }\end{array}$} & \multicolumn{2}{|c|}{$\begin{array}{l}\text { Fixation count } \\
\text { (n) }\end{array}$} \\
\hline & & & Mean & SE & Mean & $\mathrm{SE}$ & Mean & SE \\
\hline A-1 & No makeup & $22 / 22$ & 2.26 & 0.22 & 0.74 & 0.09 & 2.59 & 0.29 \\
\hline$A-4$ & Base makeup & $19 / 22$ & 3.40 & 0.41 & 0.46 & 0.11 & 1.59 & 0.28 \\
\hline$A-5$ & A-4 + lip makeup & $9 / 22$ & 3.73 & 0.74 & 0.17 & 0.06 & 0.73 & 0.22 \\
\hline A-6 & A-4 + eye makeup & $15 / 22$ & 3.61 & 0.44 & 0.34 & 0.07 & 1.19 & 0.25 \\
\hline \multirow{8}{*}{$P$ value } & A-1 vs. A-4 & & 0.079 & N.S. & 0.045 & * & 0.053 & N.S. \\
\hline & A-1 vs. A-5 & & 0.106 & N.S. & $<0.001$ & $* *$ & $<0.001$ & $* *$ \\
\hline & A-1 vs. A-6 & & 0.035 & * & 0.012 & $*$ & 0.008 & $* *$ \\
\hline & A-4 vs. A-5 & & 0.961 & N.S. & 0.045 & * & 0.053 & N.S. \\
\hline & A-4 vs. A-6 & & 0.900 & N.S. & 0.983 & N.S. & 0.756 & N.S. \\
\hline & A-5 vs. A-6 & & 1.000 & N.S. & 0.218 & N.S. & 0.379 & N.S. \\
\hline & & $\begin{array}{l}\text { Fixation } \\
\text { number }\end{array}$ & \multicolumn{2}{|c|}{$\begin{array}{l}\text { Time to first fixation } \\
\text { (s) }\end{array}$} & \multicolumn{2}{|c|}{$\begin{array}{l}\text { Total fixation duration } \\
\text { (s) }\end{array}$} & \multicolumn{2}{|c|}{$\begin{array}{l}\text { Fixation count } \\
(n)\end{array}$} \\
\hline & & $(n)$ & Mean & SE & Mean & $\mathrm{SE}$ & Mean & $\mathrm{SE}$ \\
\hline B-1 & No makeup & $15 / 22$ & 4.03 & 0.50 & 0.31 & 0.07 & 1.41 & 0.32 \\
\hline B-2 & $\begin{array}{l}\text { B-1 + point } \\
\text { makeup }\end{array}$ & $8 / 22$ & 4.84 & 0.49 & 0.16 & 0.06 & 0.45 & 0.14 \\
\hline$P$ value & B-1 vs. B-2 & & 0.173 & N.S. & 0.084 & N.S. & 0.006 & $* *$ \\
\hline
\end{tabular}

${ }^{* *} \mathrm{P}<0.01,{ }^{*} \mathrm{P}<0.05$. 
Compared with the time to first gaze fixation for A-1, that for A-6 was significantly longer $(P=0.035)$. For woman $\mathrm{B}$, the application of point makeup (B-2) tended to extend the time until the first gaze fixation compared to that without makeup (B-1), although the difference was not significant.

\section{- Total fixation duration}

The total fixation duration at the acne-affected area was significantly shorter in A-4, A-5, and A-6 than in A-1 $(P=0.045,<0.001$, and 0.012 , respectively). Fixation duration was also significantly shorter in A-5 than A-4 ( $P$ $=0.045$ ). Similarly, for woman B, the total fixation time was shorter in B-2 than B-1, but the difference was not significant.

\section{- Fixation count}

The observers looked at the acne-affected cheek significantly fewer times in A-5 and A-6 than A-1 $(P=<$ 0.001 , and 0.008 , respectively). The fixation count was also lower in A-5 and A-6 than A-4. Similarly, the fixation count was significantly lower in B-2 than B-1 $(P=0.006)$.

\subsection{Effects of Point Makeup Application and Other Strategies (Figure 4, Table 3)}

\section{- Number of observers}

Out of 22 observers, 15 and 8 fixated on the acne-affected area in the images without makeup (B-1) and with point makeup, different clothing and hairstyle, and accessories (B-3), respectively.

\section{- Time to first fixation}

The time to first fixation was shorter in B-3 than B-1, but the difference was not significant. There was no significant difference between B-2 and B-3.

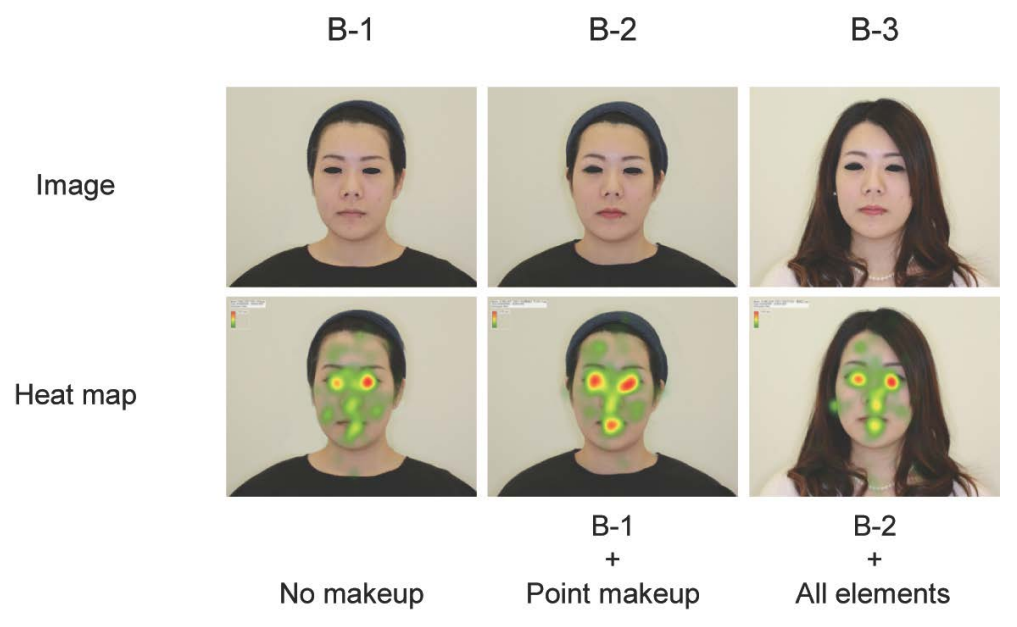

Figure 4. Combinations of makeup and non-makeup elements.

Table 3. Effects of makeup and non-makeup elements.

\begin{tabular}{|c|c|c|c|c|c|c|c|c|}
\hline & & \multirow{2}{*}{$\begin{array}{c}\text { Fixation } \\
\text { number } \\
\text { (n) }\end{array}$} & \multicolumn{2}{|c|}{$\begin{array}{l}\text { Time to first fixation } \\
\text { (s) }\end{array}$} & \multicolumn{2}{|c|}{$\begin{array}{l}\text { Total fixation duration } \\
\text { (s) }\end{array}$} & \multicolumn{2}{|c|}{$\begin{array}{l}\text { Fixation count } \\
\qquad(n)\end{array}$} \\
\hline & & & Mean & SE & Mean & $\mathrm{SE}$ & Mean & $\mathrm{SE}$ \\
\hline B-1 & No makeup & $15 / 22$ & 4.03 & 0.48 & 0.31 & 0.07 & 1.41 & 0.32 \\
\hline B-2 & B-1 + point makeup & $8 / 22$ & 4.84 & 0.49 & 0.16 & 0.06 & 0.45 & 0.14 \\
\hline \multirow[t]{2}{*}{ B-3 } & B-2 + all elements & $8 / 22$ & 3.41 & 0.47 & 0.12 & 0.07 & 0.64 & 0.28 \\
\hline & B-1 vs. B-2 & & 0.453 & N.S. & 0.157 & N.S. & 0.033 & $*$ \\
\hline \multirow[t]{2}{*}{$P$ value } & B-1 vs. B-3 & & 0.920 & N.S. & 0.018 & * & 0.049 & * \\
\hline & B-2 vs. B-3 & & 0.172 & N.S. & 0.800 & N.S. & 0.999 & N.S. \\
\hline
\end{tabular}

${ }^{* *} P<0.01,{ }^{*} P<0.05$. 


\section{- Total fixation duration}

The total fixation duration at the acne-affected area was significantly shorter in B-3 than B-1 $(P=0.018)$, but there was no significant difference between B-2 and B-3.

\section{- Fixation count}

The fixation count was significantly lower in B-3 than B-1 $(P=0.049)$. There was also no significant difference between B-2 and B-3.

\section{Discussion}

Although patients with facial dermatologic diseases are generally advised not to use cosmetics in order to avoid exacerbating their skin problems, applying makeup to cover skin manifestations improves their QOL. Hence, the usefulness of makeup is being reevaluated. However, how other people observe patients' skin manifestations and whether makeup, and other strategies, can divert others' gaze from skin lesions have not been verified.

Woman A had moderate acne and noticeable inflammatory acne lesions. Hence, the gradual application of color-correcting base makeup, particularly the concealer, which covered up noticeable acne, and the skin foundation, which adjusted the skin texture, reduced the number of observers who fixed their gaze on the acne-affected area on the right cheek, as well as extended the amount of time until the first fixation. Base makeup also tended to reduce the length of time the observers gazed at the acne-affected area. After completing the steps of successive base makeup application, nearly all variables were equivalent between woman $A$ and woman $B$, who had mild acne, without makeup.

For point makeup, either eye or lip makeup was applied in addition to the base makeup for woman A. Compared with no makeup, the time until the first gaze fixation was significantly extended, and both the number and duration of gazes were significantly reduced. When lip makeup was applied in addition to base makeup, the duration of gazes as well as the number and duration of fixation were significantly reduced. Because a significant gaze-diverting effect was observed with the application of lip and eye makeup, the choice of lipstick color and degree of eye makeup might also help divert others' gaze from the acne-affected area.

Moreover, non-makeup strategies including wearing different clothing, accessories, and having a different hairstyle tended to divert the gaze of other people from the acne-affected area. These non-makeup strategies significantly reduced the number of gazes, indicating that even when makeup cannot be fully applied, clothing, accessories, and hairstyle can be used to divert others' gaze from acne-affected areas. Accordingly, in women's daily life, makeup application, clothing, accessories, and hairstyle are generally used in combination, resulting in a gaze-diverting effect.

While other people may be less aware of a patient's skin eruptions than the patient believes them to be, acne patients who worry about their skin eruptions may try to hide these areas with their hair, by facing downward, or even by withdrawing and avoiding social encounters. As in other countries, acne is a common problem in Japan that causes personal and social difficulties, as well as reduced QOL. Eruptions on the face can hinder the social lives of young people [9] [11]. Acne eruptions can be a potential barrier in social relationships, particularly for young people [12] [13].

Designated therapeutic guidelines for treating acne have been established in Japan. The combined use of cosmetic moisturizer is reported to increase treatment adherence [14], and various other therapeutic modifications have been tried. Accordingly, the use of makeup does not appear to hinder acne treatments but actually improves patients' QOL [4]. However, applying makeup to cover skin diseases requires skills that can be taught by dermatologists and professional makeup artists [15] [16]; therefore, clinicians need to arrange proper circumstances in which guidance on makeup can be given to acne patients.

\section{Conclusion}

In conclusion, makeup can be useful for acne patients by diverting others' gaze from lesions. Considering this behavioral change in observers and the resultant psychological effect on the person, makeup may be useful for acne patients. Therefore, it should be actively integrated into acne management.

\section{References}

[1] Tanioka, M. and Miyachi, Y. (2008) Waterproof Camouflage Age for Vitiligo of the Face using Cavilon 3M as a Spray. 
European Journal of Dermatology, 18, 93-94.

[2] Tanioka, M., Yamamoto, Y., Kato, M. and Miyachi, Y. (2010) Camouflage for Patients with Vitiligo Vulgaris Improved their Quality of Life. Journal of Cosmetic Dermatology, 9, 72-75. http://dx.doi.org/10.1111/j.1473-2165.2010.00479.X

[3] Hayashi, N., Imori, M., Yanagisawa, M., Seto, Y., Nagata, O. and Kawashima, M. (2005) Make-Up Improves the Quality of Life of Acne Patients without Aggravating Acne Eruptions during Treatments. European Journal of Dermatology, 15, 284-287.

[4] Matsuoka, Y., Yoneda, K., Sadahira, C., Katsuura, J., Moriue, T. and Kubota, Y. (2006) Effects of Skin Care and Makeup under Instructions from Dermatologists on the Quality of Life of Female Patients with Acne Vulgaris. The Journal of Dermatology, 33, 745-752. http://dx.doi.org/10.1111/j.1346-8138.2006.00174.x

[5] Levy, L.L. and Emer, J. (2012) Emotional Benefit of Cosmetic Camouflage in the Treatment of Facial Skin Conditions: Personal Experience and Review. Clinical, Cosmetic and Investigational Dermatology, 5, 173-182.

[6] Maner, J.K., Kenrick, D.T., Becker, D.V., Delton, A.W., Hofer, B., Wilbur, C.J., et al. (2003) Sexually Selective Cognition: Beauty Captures the Mind of the Beholder. Journal of Personality and Social Psychology, 85, 1107-1120. http://dx.doi.org/10.1037/0022-3514.85.6.1107

[7] Kang, O.S., Chang, D.S., Jahng, G.H., Kim, S.Y., Kim, H., Kim, J.W., et al. (2012) Individual Differences in Smoking-Related Cue Reactivity in Smokers: An Eye-Tracking and fMRI Study. Progress in Neuro-Psychopharmacology and Biological Psychiatry, 38, 285-293. http://dx.doi.org/10.1016/j.pnpbp.2012.04.013

[8] Dreiseitl, S., Pivec, M. and Binder, M. (2012) Differences in Examination Characteristics of Pigmented Skin Lesions: Results of an Eye Tracking Study. Artificial Intelligence in Medicine, 54, 201-205. http://dx.doi.org/10.1016/j.artmed.2011.11.004

[9] Lee, I.S., Lee, A. R., Lee, H., Park, H. J., Chung, S. Y., Wallraven, C., et al. (2013) Psychological Distress and Attentional Bias toward Acne Lesions in Patients with Acne. Psychology, Health \& Medicine, 19, 680-686. http://dx.doi.org/10.1080/13548506.2014.880493

[10] Hayashi, N., Akamatsu, H. and Kawashima, M. (2008) Establishment of Grading Criteria for Acne Severity. The Journal of Dermatology, 35, 255-260. http://dx.doi.org/10.1111/j.1346-8138.2007.00403.x-i1

[11] Timms, R.M. (2013) Moderate Acne as a Potential Barrier to Social Relationships: Myth or Reality? Psychology, Health \& Medicine, 18, 310-320. http://dx.doi.org/10.1080/13548506.2012.726363

[12] Hayashi, N., Higaki, Y., Kawamoto, K., Kamo, T., Shimizu, S. and Kawashima, M. (2004) A Cross-Sectional Analysis of Quality of Life in Japanese Acne Patients Using the Japanese Version of Skindex-16. The Journal of Dermatology, 31, 971-976. http://dx.doi.org/10.1111/j.1346-8138.2004.tb00639.X

[13] Kubota, Y., Shirahige, Y., Nakai, K., Katsuura, J., Moriue, T. and Yoneda, K. (2010) Community-based Epidemiological Study of Psychosocial Effects of Acne in Japanese Adolescents. The Journal of Dermatology, 37, 617-622. http://dx.doi.org/10.1111/j.1346-8138.2010.00855.X

[14] Munehiro, A., Murakami, Y., Shirahige, Y., Nakai, K., Moriue, T., Matsunaka, H., et al. (2012) Combination Effects of Cosmetic Moisturisers in the Topical Treatment of Acne Vulgaris. Journal of Dermatological Treatment, 23, 172176. http://dx.doi.org/10.3109/09546634.2010.551109

[15] Seite, S., Deshayes, F., Dréno, B., Misery, L., Reygagne, F., Saiag, F., et al. (2012) Interest of Corrective Makeup in the Management of Patients in Dermatology. Clinical, Cosmetic and Investigational Dermatology, 5, 123-128.

[16] Peuvrel, L., Quéreux, G., Brocard, A., Saint-Jean, M., Vallet, C., Mère, A., et al. (2012) Evaluation of Quality of Life after a Medical Corrective Make-Up Lesson in Patients with Various Dermatoses. Dermatology, 224, 374-380. http://dx.doi.org/10.1159/000339478 